\title{
Excursions
}

Volume 4, Issue 1 (June 2013) Science/Fiction

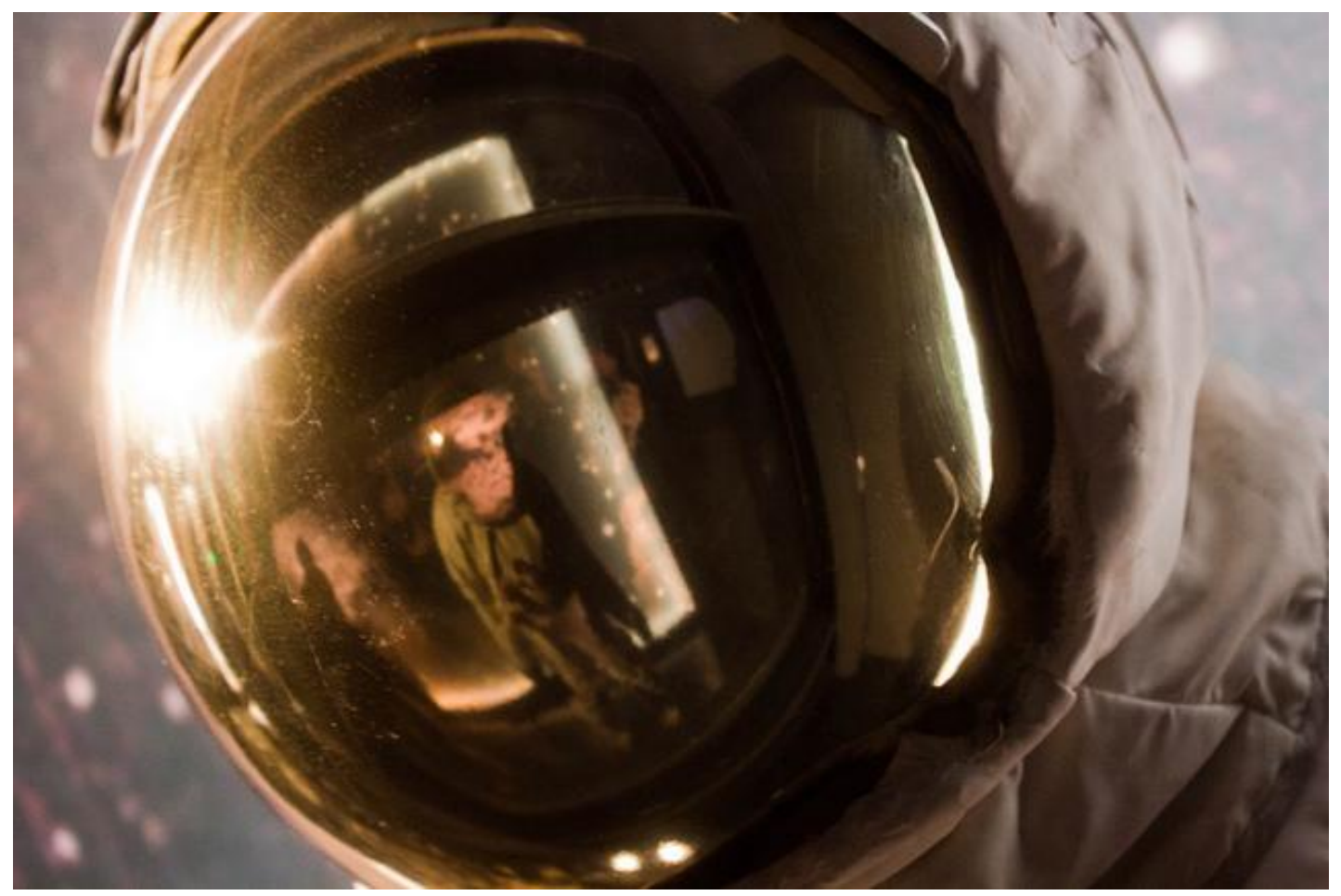

Image credit: Tangi Bertin (www.flickr.com/photos/tangi_bertin/) CC by 2.0

Ryan Porter, "Mythical Pasts, Speculative Futures: The Plasticity of the Post/Pre-Human Body",

Excursions, vol. 4, no. 1 (2013)

www.excursions-journal.org.uk/index.php/excursions/article/view/ 
Ryan Porter

Algonquin College

\section{Mythical Pasts, Speculative Futures: The Plasticity of the Post/Pre-Human Body}

Human plasticity, or the notion of a malleable, shape-shifting physical body, is a suitably pliable concept. It is an idea, often a wish-image, that populates speculative visions and stories of both the distant past and unknowable future; it is found in such diverse narratives as Aboriginal mythology and prophecies of a distant, technological future. This paper explores two vastly different incarnations of the plastic figure and suggests that its symbolic value is, suitably, adaptable to situations of which we can know only very little. Initially, this paper explores the plastic figure that occurs in the theories of futurist and technological visionary Raymond Kurzweil, whose projection of the future, contained in his theory of the technological "Singularity," foresees an imminent and fundamental shift in human life as organic matter is spliced with nanotechnology. After suggesting that Kurzweil's plastic figure inhabits a type of mythological future, I then examine the relational significance of a plastic figure that appears in North-American Aboriginal narratives of the mythical past. Kurzweil's mythical vision for humanity's ultimate "expanded plasticity" recalls, indeed finds precedent in, a figure from North-American Indigenous storytelling: the Shape Shifter, Coyote, Raven, or the Trickster. 
This paper examines the function of each plastic vision and suggests that it is a tool, a narrative device even, that both populates and helps illuminate what lies beyond the boundaries of human understanding.

Raymond Kurzweil is an inventor, computer scientist, and arguably the world's leading prophet of our technological future. He also posits an extremely resonant vision for the future in which he foresees a unison of organic and technological material through the possibilities inherent in nanotechnology. This hybrid promises a perpetual material abundance and experiential variety, since humanity will be unbounded by biological restraint and imperative, as outlined in Kurzweil's The Singularity is Near (2005). Because of nanotechnology's potential to manipulate material at the molecular level, not only humans but also the total physical environment will be fully mutable, as the body version "3.0" will "be able to alter [its] physical manifestation" as a result of its "greatly expanded plasticity" (p.310).

The "Singularity" that Kurzweil refers to in the title of his book is the point at which "human life will be irreversibly transformed" by the exponential growth made possible by Artificial Intelligence combined with nanotechnology; technological progression will, at the point of the Singularity, redefine the world so that the ontological paradigms of today are fully obsolete. Kurzweil anticipates the mutability of the post-Singularity human at the molecular level. This plastic form will allow one to adopt any physical appearance he or she desires through the ability of nanorobots to arrange molecules as if they were merely cargo. The veritable omnipotence this will afford humans, Kurzweil claims, will not only allow us to adopt any form we wish, but will also provide for the immediate satisfaction of momentary whims and desires, including erotic encounters "with our favourite entertainment star" (2005, p.318).

What might sound like simulacra limited by the inadequacies of virtual reality environments, will, in fact, be something more akin to the holodeck on the Starship Enterprise, a virtual playground in which crewmembers could vacation in any location of their choosing, accompanied by any companion they so desire: the major difference being that the experiencing subject in Kurzweil's vision will be as variable as his or her surroundings. Kurzweil also predicts that within a few hundred years humans will have found a way to break the speed of light and will "colonize the rest of the universe with our 
intelligence" (2005, p.353). All of these modifications, Kurzweil insists, do not add up to a "post-human" condition, since, to him, "being human means being part of a civilization that seeks to extend its boundaries" (2005, p.374). Far from considering the condition of plasticity as unnatural, Kurzweil views the stable biological human form as a restraining shackle, indeed, an unnatural fetter preventing us from evolving to our full potential. The limitations of the "unenhanced human," or the human body "v. 1.o," he suggests, are limitations that can and should be overcome through the fusion of the organic with the non-organic, a technological augmentation that, as he portrays it, is merely the continuation of human evolution (2005, p.7). Humans can still be human, insists Kurzweil, "even if they are not biological." His vision of the postSingularity species simply represents "the next step in evolution, the next high-level paradigm shift" (2005, p.30). Yet it also means launching humans into an era in which space, time, and age will have become irrelevant; humans will have entered a non-space where distance has no meaning and age no import.

Kurzweil is one of the best known of what Robert Geraci calls "pop scientists," and Geraci claims that, regardless of whether or not their predictions are plausible, they are significant precisely because they "frame public discussion of new sciences and technologies" (2010, p.1004). And Kurzweil's book has made a significant impact: it was a New York Times bestseller; it ranked as Amazon's number one book in Science, Philosophy, Technology and Evolution; it became the subject of an entire issue of the IEEE Spectrum, a leading journal in the Electrical and Electronics field; and it spawned numerous interviews and profiles in major print publications and on prominent television and radio programs. The sheer amount of coverage given to Kurzweil's theories in such diverse and far-reaching outlets as CNN, The Daily Show, The Charlie Rose Show, Oprah Magazine, and The New York Times, to name a few (all of which are available under the press section on singularity.com), suggests that the appeal of Kurzweil's vision goes beyond that of most futurist's forecasts.

In the scientific community, however, Kurzweil has a reputation as both a serious commentator on the technological trajectory of contemporary society, as well as an ill-informed prognosticator whose theories unknowingly echo logical and scientific fallacies. Chris Edwards states that Kurzweil's predictions 
incorporate three major errors: the assumption that technological growth according to an "S-curve" will continue to be exponential without acknowledgement of the practical and economic limits usually placed on technological growth; the use of the anthropic principle to explain the future, whereas it can only be used to explain events in the past; and the prediction that physicists will have found a way to surpass the speed of light without offering any evidence, apart from his faith in technology's ability to break barriers, to suggest that this limit can be broken (2011, pp.20-21). Furthermore, he is given serious attention in academic circles, yet that attention is more often than not in contention with his vision of the future. For instance, most contributors to the 2008 issue of the IEEE Spectrum suggest that Kurzweil's futuristic vision is "at best a long way off and probably impossible altogether" (Geraci, 2010, p.1013). Yet why does Kurzweil's vision remain so resonant? Why are so many invested in this latest version of immortality, made seemingly plausible through Kurzweil's unyielding statistics and figures out of which he builds his case? To address these questions, we need to examine the malleable significance of the plastic figure itself, a figure that is central to the appeal of Kurzweil's prophecies.

The most prominent and perhaps appealing component of Kurzweil's vision of the Singularity is the "greatly expanded plasticity" it will afford to the human body. Glenn Willmott has written of the proliferation of plastic figures during the modernist period, and, as Willmott reads them, not only are these figures visions of the post-human, but they also reflect the economic paradigms of the modern era. Plastic figures of the modernist age, often appearing within graphic narratives or weekly comics, reflect alternative methods of representing abundance and/or scarcity, as Willmott notes in his book Modern Animalism: "Modernist and subsequent experimental writers have imaginatively birthed generation after generation of post-human creatures who are the protagonists of an alternative economic experience, and instructively, of a dystopian, or more often utopian future for our erstwhile human history" (2012 pp.46-47). Kurzweil never views his plastic figure in such symbolic terms; he resists calling his vision utopian. Yet if we were to read the symbolism of his vision of post-Singularity human life, it is not unlike other utopias since it offers a vision of a benign future that has eliminated want, scarcity, and turmoil. It is the utopia of ultimate transcendence. 
Kurzweil's vision is unyieldingly optimistic, and the appeal of this vision hardly needs to be discussed, particularly during a period of pervasive economic and ecological anxiety.

Kurzweil surrounds his vision with a presentist logic of production and consumption; any and all experience will be available to the individual whose leisure is no longer restricted by the amount of temporal or material resources at his or her disposal. If we read Kurzweil's vision in light of Willmott's theory on the economic implications of post-human plastic figures, we see the postSingularity human, or at least Kurzweil's version of it, as a human form fully capable of adapting itself to the endless novelty of experience offered by late capitalism. As V. Barry Dauphin and Steven Abell state: “The Utopian promise of the Singularity may in part reflect the desire of contemporary men and women to live lives of endless choice and diversity, rather than lives of committed existential meaning or purpose" (2010, p.588). In other words, the Singularity promises a life of both luxury and stimulation, a life in which luxury and stimulation will no longer deposit the consumer at the terminus of ennui as variation and choice will be literally endless.

After the Singularity, humans will be physically capable of adapting to rapid and incessant variability; reinventing not only your image but your whole self will take but a flutter of moments. Post-Singularity human biology becomes analogous to, even a product of, the system in which it finds itself. If capital is presently at risk of exhausting the finite resources of the earth as well as the physical capacity of humans to embrace unyielding novelty, Kurzweil's post-Singularity human stresses that consumption can continue to increase as a result of our ability to alter physicality. His vision promulgates the full restructuring of our physical bodies in order to produce an über-consumer, one for whom fatigue is not an issue within the hyperkinetic atmosphere of late capitalism.

Kurzweil offers a vision of a post-Singularity human-the human v. 3.0that seems simultaneously strange, terrifying, and appealing. It is a vision in which humans have finally transcended their biological limitations and become godlike, omniscient, capable now of inhabiting, in perpetuity, fantastic environments of their own creation. Kurzweil's is a mythical future, a secular rapture, the culmination of technological progress that will retrospectively justify all prior techno-scientific development: a millenarian end that will 
fulfill the promise of progress as not only will the world be fully sculpted in our own image, but will also have shed any and all restriction on the expression of our wills. Kurzweil's is also a speculative future that deals with current ecological crises by simply putting them aside; he is safe in the assumption, faith even, that technology will, eventually, transcend.

While some commentators have disputed the likelihood and logic of Kurzweil's theories, others have read his book as an outrageous techno-fantasy that cannot possibly predict the future with any accuracy. In Nanovision: Engineering the Future, Colin Milburn takes aim at ostensibly clear-sighted narratives of post-Singularity life, and says that what lies beyond the "exponential increase in technological development" of the Singularity, a horizon beyond which Kurzweil clearly envisions both a fantasyland of consumer gratification and the ultimate fountain of youth, is essentially unknowable; the condition of life after the Singularity, the spike in technological development, is opaque and inherently unpredictable. "We cannot see past the Singularity," says Milburn, since "to do so would involve an entirely different way of seeing, a new epistemological orientation toward the world" (2008, p.5). And it is the much-touted advent of nanotechnology, says Milburn, which provides prognosticators with multiple narrative streams that can only offer speculations as to what's beyond the event horizon of the Singularity, and Kurzweil's narrative is merely one speculative fiction among many. Moreover, on closer inspection we see that Kurzweil's narrative also echoes certain mythical pasts.

In order to explain the wide appeal of Kurzweil's Singularity, Dauphin and Abell turn to the myth of Tantalus, the figure from Greek mythology whom they suggest reflects "humanity's desires for immortality and god-powers" (2010, p.592). Interestingly, Dauphin and Abell read the Singularity theory through the lens of psychoanalysis and argue that "it speaks to humanity's deepest desires that death can be conquered and that the human limits (to which history has accustomed us) can be erased" (2010, p.582). Because, as Milburn argues, post-Singularity existence is opaque to us, Kurzweil is essentially given a blank slate upon which to craft his vision, but what he ends up crafting is, according to Dauphin and Abell, a version of one of humankind's oldest stories. The unknowability of the distant future facilitates the vein of fantastic projections to which Kurzweil's belongs. Knowledge of this 
future is as inaccessible as that of any 'non-time' of the mythical past; just as in certain understandings of the mythical past, Kurzweil places his plastic figure of the post-Singularity era just beyond the horizon of what can be known, just outside the limits of predictability.

If the full plasticity of the human form is Kurzweil's imagined endpoint of technological development, when the body will become simply a product of our desires, we might gain some perspective on this fantastic future by turning to a similar figure that populates North-American Aboriginal mythology. Understanding the function and purpose of plastic figures in other narratives, particularly those from other cultural traditions, will not only help us to understand the symbolic value of Kurzweil's plastic figure, but also the cultural context that can produce such a vision. The plastic figure, or shape-shifter, is a figure common to North-American Indigenous myth and, depending on the region of the continent, or Turtle Island, this Trickster figure appears in the guise of Coyote, Raven, Wesageechack, Nanabush, and others. Coyote, however, does not occupy the world of the present, the world of the real. Rather, it inhabits a time and space distinct from and prior to ours.

Citing Gerald Vizenor, Alan Velie states that Trickster tales occur in a type of "'mythic time. It is a world not only separated by years, but in a different sort of time, long past and inaccessible" (1989, p.124). Velie also cites Bakhtin to state that the time in which Indigenous Trickster tales occur "lack[s] any relativity... any gradual, purely temporal progressions that might connect it with the present. [Trickster tales are] walled off absolutely from all subsequent times" (1989, p.124). If this past world of myth is "walled off" from the present world of the real, so too is the world Kurzweil envisions after the Singularity. Curiously, Milburn also refers to the Singularity as a "wall" that separates the future from the present. To see past the Singularity would require, says Milburn, the perspective of "the posthuman, the postbiological, the machinic, the cyborg, the networked, the uploaded, the synthetic, the schizophrenic, the alien, the monstrous, the wired, and the weird" (2008, p.5). To perceive what comes after the Singularity, then, requires a similar sort of mythical consciousness, the same type of exegetical narrative prowess used to understand the distant past.

Interestingly, both visions of post-Singularity and mythic past exist largely to explicate the world of the present; while the mythical past offers a 
creationist perspective on how we came to be, Kurzweil's mythical future validates our current techno-progressivism since, if we stay on the current path, we will transcend our earthly trappings and enter a numinous realm. It is his faith in technological progression, in its ability to save us largely from the problems it has also caused that pushes Kurzweil's belief towards the ecclesiastical.

It may seem too reductive to mention, but there are, of course, fundamental differences between Kurzweil's post-Singularity vision and Indigenous representations of the mythic past. First and foremost is the absence of nostalgia for the time of myth in Indigenous stories. Dell Hymes notes that there is no longing for the time before humans in Aboriginal mythology: "The present world," says Hymes with regard to Trickster stories, "was not fallen from a Golden Age, but set right" (1995, p.3). The mythical world was one of chaos, and it is the Trickster, the mythical, plastic figure that helped develop the previous world of myth into the world of the present: the solid world as it should be. And as William Bright notes, the Trickster figure of Coyote is, in many stories, the figure who "fixes [the world] up' so that it becomes the world of humanity" (1987, p.351). In the North-American Indigenous stories, the world as it is now is not the fallen world as it is in Christian myth, but the world that has been made safe for us.

One contemporary writer who remains influenced by the oral storytelling traditions of the Aboriginal People of North America, or Turtle Island, is Thomas King, a prominent Canadian writer, academic, and radio host. His Coyote stories not only retain an element of orality, as King is heavily influenced by the transcriptions of oral stories told by Okanagan elder Harry Robinson, but they also retain Coyote's function as a fixer, although he is often a comical and inefficacious one. In King's short story "The One About Coyote Going West," Grandmother narrates to her companion, Coyote, a story about the first Coyote who inhabits a time prior to the arrival of the "Indians." In Grandmother's tale, Coyote is traveling west to visit his friend Raven through a flat, featureless, almost Beckettian landscape, a landscape prior to the creation of trees, mountains, rivers, and, of course, humans. Coyote then decides to fix the world by creating all of the things in the world. The first thing Coyote makes, however, is a mistake, a mistake that then eludes Coyote and begins to fill the world up with snow tires, colour monitors, and golf carts, all of which 
the mistake finds in a catalogue while sitting atop a gas powered BBQ. While it is his mistake that congests the world with these consumer items, Coyote is simultaneously horrified at their destructive potential: "We don't need that stuff, says Coyote ... You're going to fill up this world ... You got to give me that book before the world gets lopsided" (1993, p.309). While King's story allegorizes the European domination of North-America's Indigenous population and advocates obvious ecological imperatives, his tale also continues a storytelling tradition detailing Coyote's exploits in the world prior to the present one.

In King's tale, Coyote's fixing of the world is both an improvement and a stabilization or concretization: Coyote 'fixes' the world into its present form. Grandmother ends the tale of the first Coyote by expressing her concern that the present Coyote, now having heard the story of the first Coyote, will continue the work of its forebear, and by fixing the world, will continue to make mistakes: "I can't talk anymore because I got to watch the sky. Got to watch out for falling things that land in piles. When that Coyote's wandering around looking to fix things, nobody in this world is safe" (1993, p.312). Grandmother here expresses a concern about a return of the world to the condition of myth, to a world of unpredictability, since in attempting to fix the world, Coyote simultaneously unfixes it due to the probability of additional mistakes.

In his 2003 Massey lectures, The Truth About Stories, King comments on the philosophical traditions that stem from different creation stories. King consciously writes out of a centuries-old oral tradition that understands the world as radically different from a Judeo-Christian perspective, as is apparent from his comparison of Western and Indigenous religious assumptions: "So here are our choices: a world in which creation is a solitary, individual act or a world in which creation is a shared activity; a world that begins in harmony and slides toward chaos or a world that begins in chaos and moves toward harmony" (2003, pp.24-25). He also writes that it is cultures' creation stories "that help define the nature of the universe and how cultures understand the world in which they exist” (2003, p.10). The world of the West, King writes, is dominated by a very powerful fallacy: "God's Chosen People. The Alpha and the Omega. Masters of the Universe. It is this conceit we continue to elaborate as we fill up our tanks at the gas station [...] The lie we dangle in front of our 
appetites as we chase progress to the grave" (2003, p.28). Kurzweil's Singularity narrative is the full manifestation of this fallacy.

King and Kurzweil present radically divergent views on the nature and value of plasticity, views that distinctly relate to the cultural tradition out of which each is writing. Kurzweil wants to 'fix' us by 'unfixing' us, and sees this final plasticity as the end point of our techno-progressive aspirations. At the heart of Kurzweil's theory rests the same recovery narrative that seeks to redeem humankind from its inherent or original flaw. The boundaries of that recovery narrative have shifted inward; the frontier has moved internal to the human body in the quest of destabilizing our very form, and, perhaps, continuing the quest of escaping ourselves. The "greatly expanded plasticity" of the post-Singularity human will conclude the narrative that began with the expulsion from the Garden of Eden; while there may not appear to be anything nostalgic about Kurzweil's predictions, they are informed by an inherent longing to transcend and return to a world in which the distinction of the self from the world of things is blurred, where there is no gap between desire and fulfillment.

Again, in The Truth About Stories King cites Gerald Vizenor when he states: “The truth about stories is that that's all we are. 'You can't understand the world without telling a story [...] There isn't any center to the world but a story" (2003, p.32). Despite the meticulous detail, charts, and voluminous knowledge of technological trends that Kurzweil uses to lay out his theory, he is, in essence, merely telling a story, and a story that isn't as unfamiliar or as novel as it may at first seem. The "greatly expanded plasticity" of the postSingularity human is Kurzweil's version of our path back to the garden, our escape from this fallen world, and our entrance into one of eternal jouissance, all cloaked in the rhetoric of scientific plausibility. Turning to Vizenor directly, we see that he calls the Indigenous Trickster figure "a liberator and healer in a narrative" (Vizenor to Isernhagen, 1999, p.187). And in King's narrative at least, Coyote heals the world from chaos; it is plasticity that North-American Indigenous myth wants to transcend as opposed to seeing it as the marker of transcendence. Both visions of past and future are myths, stories about the nature of ourselves and the world as it is, yet only one of these stories sees any value in our present incarnation. 


\section{Bibliography}

Bright, W., 1987. The Natural History of Old Man Coyote. In: B. Swann and A. Krupat, eds., Recovering the word. Berkeley: University of California Press, pp. $339-387$

Dauphin, B. V. and Abell, S., 2010. Infinite adolescence: a psychoanalytic exploration of tantalizing promises inherent to the singularity. Psychoanalytic Review, 97(4), pp. 579-605

Edwards, C., 2011. The singularity isn't even close. Skeptic Magazine, 16(2), pp. 2021

Geraci, R.M., 2010. Artificial intelligence, networks, and spirituality: the popularity of apocalyptic AI. Zygon: Journal of Religion and Science, 45(4), pp.10031020

Hymes, D., 1995. Coyote: polymorphous but not always perverse. Weber Studies: An Interdisciplinary Humanities Journal, 12(3), pp.79-92

King, T., 1993. The one about Coyote going west. In: R. Brown and D. Bennett, eds. 2005. Canadian Short Stories. Toronto: Pearson Education, pp. 302-312 2003. The truth about stories. Toronto: Anansi

Kurzweil, R., 2005. The singularity is near. New York: Viking

Millburn, C., 2008. Nanovision: engineering the future. Durham: Duke University Press

Velie, A., 1993. 'The Trickster novel.' In: G. Vizenor, ed., Narrative chance: postmodern discourse on native American Indian literatures. Albuquerque: University of New Mexico Press, pp. 121-139

Vizenor, G., 1999. 'Interview.' In: H. Isernhagen, ed., Momaday, Vizenor, Armstrong. Conversations on American Indian Writing. Norman: University of Oklahoma Press 
Excursions 4:1

Willmott, G., 2012. Modern animalism: habitats of scarcity and wealth in comics and literature. Toronto: University of Toronto Press 